\section{MEDICO RESEARCH CHRONICLES ISSN NO. 2394-3971 \\ DOI No. 10.26838/MEDRECH.2021.8.5.554}

\title{
ASSESSMENT OF ECHOCARDIOGRAPHIC LEFT VENTRICULAR DIMENSIONS
} WITH SEVERAL CLINICAL FINDINGS AMONG HEALTHY PEOPLE

Dr. Md. Emran Hossain ${ }^{1}$, Dr. Roksana Islam², Dr. Mohammad Abdur Rahim ${ }^{3}$, Dr. Khondekar Mustaq Adnan ${ }^{4}$, Dr. Molla Md. Iftekhar Hossain ${ }^{5}$, Dr. Md. Mustafizur Rahman ${ }^{6}$ 1. Assistant Professor, Department of Cardiology, Chattogram Medical College \& Hospital, Chattogram, Bangladesh

2. Lecturer, Department of Physiology, Chattogram Medical College, Bangladesh

3. Assistant Professor, Department of Medicine, Chattogram Medical College \& Hospital, Chattogram, Bangladesh

4. Consultant, Department of Medicine, Central Police Hospital, Rajarbagh, Dhaka, Bangladesh

5. Assistant Professor, Department of Cardiology, Rajshahi Medical College \& Hospital

6. Assistant Professor, Department of Cardiology, National Institute of Cardiovascular Disease (NICVD), Dhaka, Bangladesh

\section{ARTICLE INFO}

Article History

Received: July 2021

Accepted: September 2021

Keywords:

Electrocardiographic left ventricular dimensions, Clinical findings, QRS duration, MI.
AbSTRACT

ORIGINAL RESEARCH ARTICLE

Background: The echocardiographic measurement of left ventricular dimensions and the changes of left ventricular dimensions may be important to assess cardiac as well as the cardiovascular conditions of patients. On the other hand, the QRS duration signifies the time for ventricular depolarization. Aim of the study: The aim of this study was to assess the echocardiographic left ventricular dimensions with several clinical findings among healthy people. Methods: This was an observational cross-sectional study which was conducted in the Department of Cardiology, University Cardiac Centre, Bangabandhu Sheikh Mujib Medical University, Dhaka over a period of 2 years from July 2008 to June 2010. In total 92 apparently healthy people without heart failure (HF) or myocardial infarction (MI) were included as the study population. Among them, 22 were in Referent (QRS duration $<100 \mathrm{~ms}$ ), 40 in Incomplete BBB (QRS duration $100-119)$, and 30 in Complete BBB ( $\geq 120 \mathrm{~ms}$ ) groups. Proper written consent was taken from all the participants and this study was approved by the ethical committee of the mentioned university. All data were processed, analyzed, and disseminated by MS Office and SPSS version as per need. Results: In this study, the left ventricular (LV) mass, left ventricular diastolic dimension, septal wall thickness, posterior wall thickness and left atrial size were significantly higher in complete BBB group than those in referent and incomplete BBB group (143.0 \pm 30.2 vs. $182.6 \pm 37.9$ vs. $222.0 \pm 61.0, p<0.001 ; 4.6 \pm 0.3$ vs. $4.9 \pm 0.3$ vs. 
$5.2 \pm 0.4, \mathrm{p}<0.001 ; 0.9 \pm 0.1$ vs. $1.0 \pm 0.1$ vs. $1.1 \pm 0.1, \mathrm{p}<0.001 ; 0.9 \pm 0.1$ vs. $1.0 \pm 0.1$ vs. $1.1 \pm 0.1, \mathrm{p}<0.001$; and $3.3 \pm 0.3$ vs. $3.6 \pm 0.3$ vs. $3.7 \pm 0.3, \mathrm{p}<0.001$ respectively). However, fractional shortening and left ventricular ejection fraction were found to decrease significantly with the increase in QRS duration ( $\mathrm{p}<0.001$ and $\mathrm{p}<0.001$ respectively). In this study the QRS duration was observed to be linearly correlated with LV mass, LV diastolic dimension, septal wall thickness, posterior wall thickness and left atrial size $(\mathrm{r}=0.577, \mathrm{p}<0.001 ; \mathrm{r}=0.480, \mathrm{p}<0.001$; $\mathrm{r}=0.583, \quad \mathrm{p}<0.001 ; \mathrm{r}=0.521, \quad \mathrm{p}<0.001$ and $\mathrm{r}=0.418, \quad \mathrm{p}<0.001$ respectively). However, QRS duration was found to maintain a negative correlation with fractional shortening and LVEF ( $\mathrm{r}=-0.637$, $\mathrm{p}<0.001$ and $\mathrm{r}=-0.701, \mathrm{p}<0.001$ respectively). Conclusion: The present study revealed that longer electrocardiographic QRS duration was correlated with the increase in LV mass, LV diastolic dimensions, septal wall thickness, posterior wall thickness, and left atrial size. The association was most striking in individuals with complete BBB compared with a normal QRS duration. Meanwhile, the presence of prolonged QRS in a patient's ECG can serve as a bedside clue to the

Corresponding author Dr. Md. E. Hossain* presence of decreased fractional shortening and left ventricular ejection fraction.

2021, www.medrech.com

\section{INTRODUCTION}

The echocardiographic measurement of left ventricular dimensions and the changes of left ventricular dimensions are important to assess cardiac as well as the cardiovascular conditions of patients. On the other hand, the QRS duration signifies the time for ventricular depolarization. The QRS duration signifies the time for ventricular depolarization. Normally, the QRS duration is 0.06 to 0.10 seconds. The measurement of left ventricular dimensions and the changes of left ventricular dimensions are important to assess cardiac as well as the cardiovascular conditions of patients. Corelations between electrocardiographic QRS duration with other clinical findings among healthy people may help in assessing the cardio-vascular condition of cardiac patients. With the advent of ECG, a revolutionary change in the diagnosis and management of heart diseases was made with a consequent decrease in mortality and morbidity. The broad application of ECG as a screening tool and its easy access has made it one of the most common diagnostic tests performed in routine clinical practice. $^{1}$ The 12-lead electrocardiogram (ECG) is the most readily available non-invasive test for the detection of cardiac disease. ${ }^{2}$ Recent advances have extended the importance of ECG in determining the extent and severity of myocardial ischemia, localizing sites of origin and pathways of tachyarrythmias, assessing therapeutic options for patients with heart failure, and identifying and evaluating patients with the genetic disease who are prone to arrhythmias. ${ }^{3}$ In ECG the P wave is generated by activation of the atria. The PR segments represent the duration of atrioventricular conduction, The QRS complex is produced by activation of both ventricles, and the ST-T wave reflects ventricular recovery. ${ }^{3}$ A normal ventricular activation is a complex event that is dependent on interactions between the physiology and anatomy of the specialized ventricular conducting system and the ventricular myocardium. The net result is the multiphasic QRS complex. The overall QRS 
complex may be described as QRS if it consists of an initial small negative wave (the q wave) followed by a tall upright one (The $R$ wave) and a deeply negative one (an $\mathrm{S}$ wave). ${ }^{3}$ The upper normal value for QRS duration is traditionally given as shorter than 120 milliseconds measured in the lead with the widest QRS duration. Women, on average, have a somewhat smaller QRS duration than men (by about 5 to 8 milliseconds). ${ }^{3}$ A prolonged electrocardiographic QRS duration $(\geq 120 \mathrm{~ms})$ may be a marker of inter or intraventricular mechanical dyssynchrony and has been associated with adverse prognosis in systolic heart failure. ${ }^{4}$ A wide QRS may be helpful in identifying the presence of interventricular dyssynchrony but it may not be related to intraventricular dyssynchrony. ${ }^{5}$ Experimental investigations suggest that asynchronous LV contraction (indicated by prolonged electrocardiographic QRS duration) may promote LV remodeling, manifested by increases in wall thickness of late-activated LV segments.4 Prolongation of QRS duration may be the result of LV dilatation, with a concomitant increase in conduction time of the cardiac impulse. ${ }^{4}$ It is possible that prolongation of the QRS complex is a marker of dyssynchronous LV contraction. In the redistribution of mechanical load \& differential hypertrophy of the late activated LV segments, such non-coordinated mechanical contraction of the ventricle results. ${ }^{6}$ Patients with a prolonged QRS duration $(>0.10 \mathrm{~s})$ had lower left ventricular ejection fraction (LVEF) compared to patients with a normal QRS duration. In patients with QRS duration $>0.10 \mathrm{~s}$, there is a high likelihood that the resting LVEF will be abnormal. $^{7} \quad$ Prolongation of electrocardiographic QRS interval is found to be associated with increased echocardiographic left-ventricular (LV) mass cross-sectionally in individuals without prior history of congestive (CHF) or myocardial infarction (MI). This observation raises the possibility that prolongation of the QRS duration may be a marker of adverse ventricular remodeling. ${ }^{4}$ As part of the Framingham Heart Study, determined CV risk in 70 patients with RBBB who were followed for up to 18 years, Schneider et al., ${ }^{\mathbf{8}}$ In that study, the $\mathrm{CV}$ mortality was three times greater in patients with RBBB than in an agematched sample of the population at large. ECGs with QRS duration greater than $130 \mathrm{~ms}$ $\mathrm{CV}$ abnormalities such as HF were most likely to have been associated. These same investigators studied 55 patients who developed LBBB and found that the QRS duration did not correlate with the prevalence of associated CV abnormalities. ${ }^{9}$ In men with LBBB versus $\mathrm{RBBB}$, a higher mortality rate from $C V$ disease was seen. This rate was higher than in women with either conduction abnormality. ${ }^{\mathbf{1 0}}$ Kreger et al. ${ }^{\mathbf{1 1}}$ found the ageadjusted incidence of MI, angina pectoris, and coronary death to be unrelated to baseline QRS prolongation.

\section{OBJECTIVES \\ General Objective:}

To assess the echocardiographic left ventricular dimensions with several clinical findings among healthy people.

\section{Specific Objective:}

- To collect information regarding the demo-graphic status of the participants.

- To collect information regarding the electrocardiographic variables among participants.

- To collect information regarding the clinical variables among participants.

- To collect information regarding the echocardiographic variables among participants.

- To assess the correlation of QRS duration with LV diastolic dimensions and LV mass among participants.

\section{METHODOLOGY \& MATERIALS}

This cross-sectional study was conducted in the Department of Cardiology, University Cardiac Centre, Bangabandhu 
Sheikh Mujib Medical University, Dhaka over a period of 2 years from July 2008 to June 2010. In total 92 apparently healthy people without heart failure (HF) or myocardial infarction (MI) were included as the study population. Among them, 22 were in Referent (QRS duration $<100 \mathrm{~ms}$ ), 40 in Incomplete BBB (QRS duration 100 - 119), and 30 in Complete BBB ( $\geq 120 \mathrm{~ms})$ groups. According to the inclusion criteria of this study, healthy people of age between 25 and 80 years are free from heart failure (HF) and myocardial infarction (MI) with proper documents of computerized electrocardiogram (ECG) and 2D \& M-mode echocardiographic variables available were included. On the other hand, according to the exclusion criteria of this study patients with prevalent heart failure, myocardial infarction (MI), digoxin or quinidine use, and history of permanent pacemaker (PPM) implantation were excluded. The demographic variables included in the study were age, sex, BMI, and smoking habit. The clinical variables were systolic BP, diastolic BP, diabetes mellitus (DM), and the use of antihypertensive medications. Data were collected by interview, observation, and clinical examination. Complete medical history, clinical examination, and assessment of cardiovascular risk factors like hypertension and diabetes mellitus, clinical examination, and relevant investigations reports like ECG and echocardiography of all patients were recorded in a pre-designed data collection sheet. All the participants underwent electrocardiographic (ECG) and 2D and Mmode echocardiographic examination. Hypertension was considered if the patient was on oral antihypertensive medication and/or systolic blood pressure $>140 \mathrm{mmHg}$ and diastolic blood pressure $>90 \mathrm{mmHg}$. Left ventricular fractional shortening and LVEF were considered as indicators of LV systolic function. Diabetes mellitus (DM) was considered if the patient was on oral antidiabetic medications or had fasting blood glucose $>7 \mathrm{mmol} / \mathrm{L}$ or two hours after postprandial plasma glucose $>11.1 \mathrm{mmol} / \mathrm{L}$ or $>200 \mathrm{mg} / \mathrm{dl}$. Cigarette (any amount within first three years), significant smoking history were defined as $>10$ Pack years of cigarette use. Overweight and obesity were defined according to NIH 1998 Guidelines. All data were processed and analyzed and disseminated by using SPSS version 11.5 and MS Office as per need.

\section{RESULT}

In this study we observed, the ages were almost identically distributed among the three categories of patients based on QRS duration (53.2 $\pm 11.6,52.1 \pm 7.4$, and 55.8 9.4 years respectively, $\mathrm{p}=0.242$ ). Male patients comprised the main bulk in complete BBB $(76.7 \%)$, while females were predominant in the referent group $(59.1 \%)$. The mean $( \pm S D)$ QRS duration of Referent, Incomplete BBB, and Complete BBB group participants were found $88.3 \pm 7.1,106.9 \pm 4$, and $162.4 \pm 15.8$ ms respectively. On the other hand, the mean $( \pm$ SD) QRS voltages were $1195.4 \pm 359.2$, $1312.5 \pm 390.4$ and $1587.7 \pm 942.9 \mu \mathrm{v}$ respectively. In this study, the left ventricular (LV) mass, left ventricular diastolic dimension, septal wall thickness, posterior wall thickness and left atrial size were significantly higher in complete BBB group than those in referent and incomplete BBB group (143.0 \pm 30.2 vs. $182.6 \pm 37.9$ vs. $222.0 \pm$ $61.0, \mathrm{p}<0.001 ; 4.6 \pm 0.3$ vs. $4.9 \pm 0.3$ vs. $5.2 \pm$ $0.4, \mathrm{p}<0.001 ; 0.9 \pm 0.1$ vs. $1.0 \pm 0.1$ vs. $1.1 \pm$ $0.1, \mathrm{p}<0.001 ; 0.9 \pm 0.1$ vs. $1.0 \pm 0.1$ vs. $1.1 \pm 0.1, \mathrm{p}<0.001$; and $3.3 \pm 0.3$ vs. $3.6 \pm 0.3$ vs. $3.7 \pm 0.3, p<0.001$ respectively). However, fractional shortening and left ventricular ejection fraction were found to decrease significantly with the increase in QRS duration ( $\mathrm{p}<0.001$ and $\mathrm{p}<0.001$ respectively). In this study the QRS duration was observed to be linearly correlated with LV mass, LV diastolic dimension, septal wall thickness, posterior wall thickness and left atrial size $(r=0.577, \quad \mathrm{p}<0.001 ; \mathrm{r}=0.480$, 
$\mathrm{p}<0.001 ; \mathrm{r}=0.583, \mathrm{p}<0.001 ; \mathrm{r}=0.521, \mathrm{p}<0.001$ and $\mathrm{r}=0.418, \mathrm{p}<0.001$ respectively). However, QRS duration was found to maintain negative correlation with fractional shortening and LVEF ( $r=-0.637, p<0.001$ and $r=-0.701$, $\mathrm{p}<0.001$ respectively).

Table I: Comparison of demographic characteristics among groups (N=92)

\begin{tabular}{|c|c|c|c|c|}
\hline \multirow[t]{2}{*}{ Characteristics } & Referent & Incomplete BBB & Complete & \multirow[t]{2}{*}{ p-Value } \\
\hline & $(n=22)$ & $(\mathrm{n}=40)$ & $\operatorname{BBB}(n=30)$ & \\
\hline \multicolumn{5}{|c|}{ Age distribution in years (Mean \pm SD) } \\
\hline Age & $53.2 \pm 11.6$ & $52.1 \pm 7.4$ & $55.8 \pm 9.4$ & $0.242^{\mathrm{ns}}$ \\
\hline \multicolumn{5}{|l|}{ Gender distribution } \\
\hline Male & $9(40.9)$ & $22(55.0)$ & $23(76.7)$ & \multirow[t]{2}{*}{$0.029^{\mathrm{s}}$} \\
\hline Female & $13(59.1)$ & $18(45.0)$ & $7(23.3)$ & \\
\hline \multicolumn{5}{|c|}{ BMI (kg/m2) distribution } \\
\hline$<25$ (normal) & $15(68.2)$ & $22(55.0)$ & $7(23.3)$ & \multirow[t]{2}{*}{$0.003^{\mathrm{s}}$} \\
\hline$\geq 25$ (Over-wt. \& obese) & $7(31.8)$ & $18(45.0)$ & $23(76.7)$ & \\
\hline \multicolumn{5}{|c|}{ Smoking habits among participants } \\
\hline Yes & $5(22.7)$ & $9(22.5)$ & $8(26.7)$ & \multirow[t]{2}{*}{$0.911^{\mathrm{ns}}$} \\
\hline No & $17(77.3)$ & $31(77.5)$ & $22(73.3)$ & \\
\hline
\end{tabular}

Table II: Electrocardiographic variables among participants (N=92)

\begin{tabular}{|c|c|c|c|c|}
\hline \multirow[t]{2}{*}{ Variables } & Referent & Incomplete BBB & Complete BBB & \multirow{2}{*}{$\begin{array}{c}\text { p- } \\
\text { Value }\end{array}$} \\
\hline & $(n=22)$ & $(n=40)$ & $(n=30)$ & \\
\hline QRS duration (ms) & $88.3 \pm 7.1$ & $106.9 \pm 4.5$ & $162.4 \pm 15.8$ & $<0.05^{\mathrm{s}}$ \\
\hline QRS voltage $(\mu v)$ & $1195.4 \pm 359.2$ & $1312.5 \pm 390.4$ & $1587.7 \pm 942.9$ & $<0.05^{\mathrm{s}}$ \\
\hline
\end{tabular}

Table III: Clinical variables among the three groups (N=92)

\begin{tabular}{|l|c|c|c|c|}
\hline \multirow{2}{*}{ Characteristics } & Referent & Incomplete BBB & Complete & \multirow{2}{*}{ p-Value } \\
\cline { 2 - 4 } & $(\mathrm{n}=22)$ & $(\mathrm{n}=40)$ & BBB $(\mathrm{n}=30)$ & \\
\hline Systolic BP & $125.8 \pm 27.7$ & $130.1 \pm 12.3$ & $129.8 \pm 14.5$ & $0.652^{\mathrm{ns}}$ \\
\hline Diastolic BP & $77.9 \pm 6.4$ & $79.1 \pm 6.7$ & $76.3 \pm 6.7$ & $0.225^{\mathrm{ns}}$ \\
\hline Antihypertensive used & $2(9.1)$ & $4(10.0)$ & $8(26.7)$ & $0.104^{\mathrm{ns}}$ \\
\hline Diabetes & $3(13.6)$ & $5(12.5)$ & $8(26.7)$ & $0.262^{\mathrm{ns}}$ \\
\hline
\end{tabular}

Table IV: Echocardiographic variables among participants (N=92)

\begin{tabular}{|l|c|c|c|l|}
\hline \multicolumn{1}{|c|}{ Variables } & Referent & Incomplete BBB & Complete BBB & \multirow{2}{*}{ p- Value } \\
\cline { 2 - 4 } & $(\mathrm{n}=22)$ & $(\mathrm{n}=40)$ & $(\mathrm{n}=30)$ & \\
\hline LV mass & $143.0 \pm 30.2$ & $182.6 \pm 37.9$ & $222.0 \pm 61.0$ & $<0.001^{\mathrm{s}}$ \\
\hline LV diastolic dimension & $4.6 \pm 0.3$ & $4.9 \pm 0.3$ & $5.2 \pm 0.4$ & $<0.001^{\mathrm{s}}$ \\
\hline Septal wall thickness & $0.9 \pm 0.1$ & $1.0 \pm 0.1$ & $1.1 \pm 0.1$ & $<0.001^{\mathrm{s}}$ \\
\hline Posterior wall thickness & $0.9 \pm 0.1$ & $1.0 \pm 0.1$ & $1.1 \pm 0.1$ & $<0.001^{\mathrm{s}}$ \\
\hline Fractional shortening & $36.2 \pm 2.1$ & $33.4 \pm 2.9$ & $30.1 \pm 2.7$ & $<0.001^{\mathrm{s}}$ \\
\hline Left atrial size & $3.3 \pm 0.2$ & $3.6 \pm 0.3$ & $3.7 \pm 0.3$ & $<0.001^{\mathrm{s}}$ \\
\hline LVEF & $70.9 \pm 3.3$ & $65.6 \pm 5.5$ & $58.3 \pm 4.5$ & $<0.001^{\mathrm{s}}$ \\
\hline
\end{tabular}




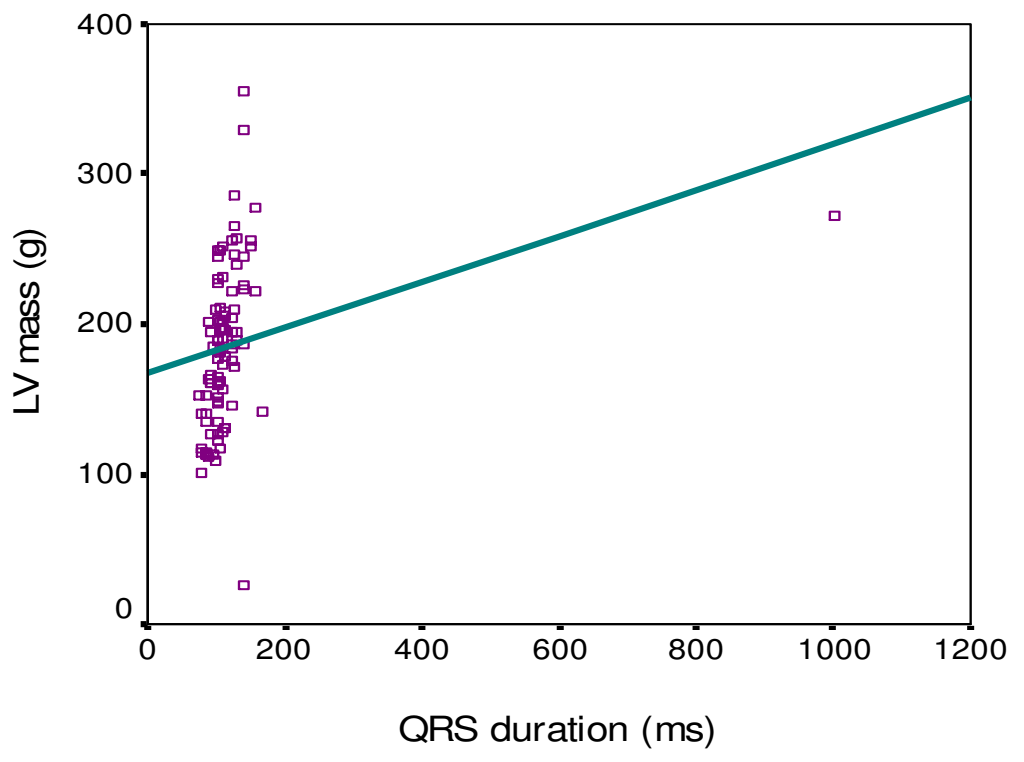

Figure I: Correlation between QRS duration and LV mass

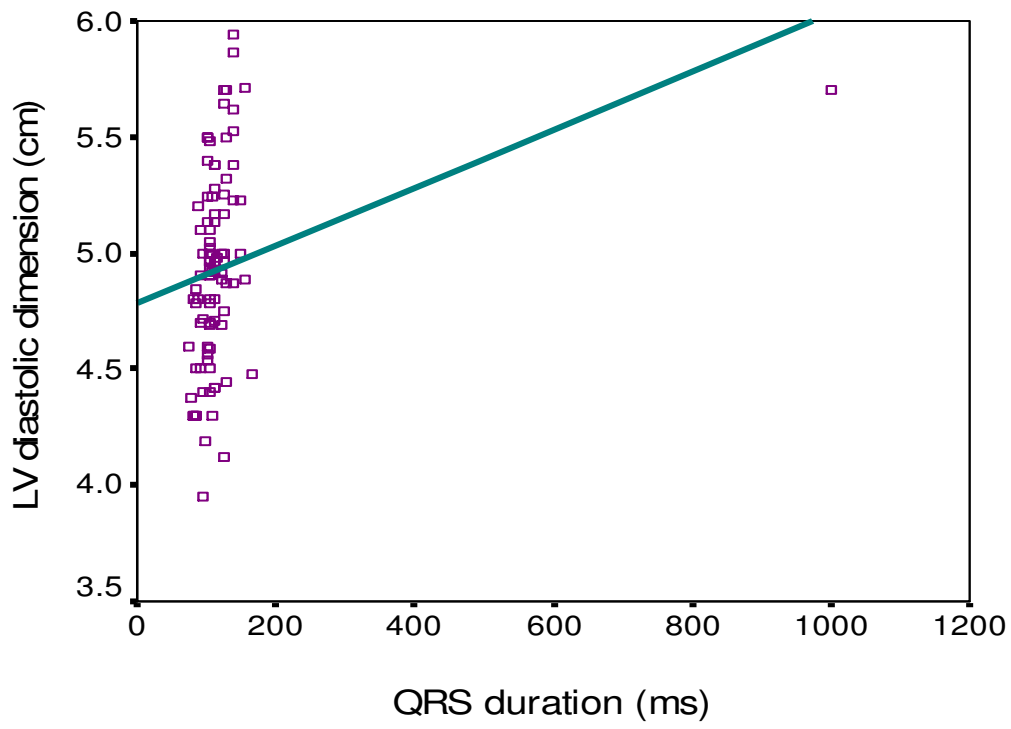

Figure II: Correlation between QRS duration and LV diastolic dimensions

\section{DISCUSSION}

The aim of this study was to assess the echocardiographic left ventricular dimensions with several clinical findings among healthy people. The result of the current study demonstrated that age was almost identically distributed among the three categories of patients based on QRS duration (53.2 \pm 11.6 in referent, 52.1 \pm .4 in incomplete $\mathrm{BBB}$, and $55.8 \pm 9.4$ years in complete BBB group respectively, $\mathrm{p}=0.242$ ). The complete $\mathrm{BBB}$ was significantly common in male patients (76.7\%), while females were predominant in the referent group $(59.1 \%)(\mathrm{p}=0.029)$. Overweight and obese subjects were significantly less in the referent group $(31.8 \%)$ compared to those in incomplete BBB (45\%) and complete $\mathrm{BBB}(76.7 \%)$ indicating that overweight and obesity status increases with the increase in QRS duration. Around one- 
quarter of the subjects was a smoker. Dhingra and associates $(2005)^{4}$ conducted an almost similar study where, the age distribution of subjects in referent, incomplete $\mathrm{BBB}$ and complete BBB group in man $54 \pm 14,51 \pm 14$, $61 \pm 15$ years respectively and in woman $55 \pm 15,58 \pm 15$ and $68 \pm 12$ years respectively. However, one year after the same investigators reported higher mean age in three groups (70 $\pm 7,70 \pm 7$, and $72 \pm 7$ years respectively). ${ }^{\mathbf{1 2}}$ They observed male predominance incomplete $(60 \%)$ and complete BBB $(58 \%)$, while the referent group was preoccupied with females (70\%). The BMI was almost similar among the subjects with referent, incomplete and complete BBBs. No significant difference was observed among the three groups in terms of smoking habits. Prolonged QRS duration was predominantly observed in male subjects (76.7\%) which was also found in the study of Shenkaman et al. (2002). ${ }^{7}$ In the present study, mean systolic and diastolic blood pressure were almost identically distributed among the three groups. The prevalence of diabetic patients and use of antihypertensive drugs were found highest incomplete BBB group than those in the referent and incomplete BBB group, although the difference did not turn significant. In 2006 Dhingra associates ${ }^{\mathbf{1 2}}$ reported that systolic BP was highest complete $\mathrm{BBB}$ group than those in the referent and incomplete $\mathrm{BBB}$ group, though diastolic BP was almost similar among the three groups. The mean QRS duration and mean QRS voltage were significantly highest complete $\mathrm{BBB}$ group than those in the referent and incomplete BBB group. In this regard, Dhingra's study (2006) ${ }^{\mathbf{8}}$ was almost consistent with the present study (mean QRS duration was $87 \pm 7 \mathrm{~ms}$ in referent, $106 \pm 5 \mathrm{~ms}$ in complete BBB, and $140 \pm 14 \mathrm{~ms}$ incomplete BBB group). Echocardiographic variables pertaining to $\mathrm{LV}$ function revealed that left ventricular (LV) mass, left ventricular diastolic dimension, septal wall thickness, posterior wall thickness, and left atrial size were significantly higher in the complete BBB group compared to the referent and incomplete BBB group. However, fractional shortening and left ventricular ejection fraction were observed to be decreased significantly with the increase in QRS duration. These findings are consistent with the study done by Dhingra et al., $(2005)^{4}$ who reported a significant association of increased electrocardiographic QRS duration with decreased LV fractional shortening and LV ejection fraction. QRS duration was observed to be linearly correlated with LV mass, LV diastolic dimension, septal wall thickness, posterior wall thickness and left atrial size with correlation coefficients being $\mathrm{r}=0.577, \mathrm{r}=0.480, \mathrm{r}=0.583, \mathrm{r}=0.521$, and $\mathrm{r}=0.418$ respectively.

\section{CONCLUSION AND RECOMMENDATIONS}

The echocardiographic measurement of left ventricular dimensions and the changes of left ventricular dimensions are important to assess cardiac as well as the cardiovascular conditions of patients. The present study revealed that longer electrocardiographic QRS duration was correlated with an increase in LV mass, LV diastolic dimensions, septal wall thickness, posterior wall thickness, and left atrial size. Compared with a normal QRS duration, the association was most striking in individuals with complete BBB. Meanwhile, the presence of prolonged QRS in a patient's ECG can serve as a bedside clue to the presence of decreased fractional shortening and left ventricular ejection fraction. For getting more reliable information we would like to recommend conducting more studies in several places with large sample sizes.

\section{REFERENCES}

1. Francia P, Ballac, Paneni F \& Volpem M 2007, Left bundle- branch blockpathophysiology, prognosis, and clinical management, Clin. Cardiol, vol.30, pp.110-15.

2. Murkofsy RL, Danges G, Diamond JA, Mehta D, Schaffer A \& Ambrose 
JA 1998, A prolonged QRS duration on surface electrocardiogram is a specific indicator of left ventricular dysfunction, J Amcoll Cardiol, vol.32, pp. 476-82.

3. David M, Mirvis \& Ary L. Gold berger. Electrocardiography. Brawnwald's Heart disease. A text book of cardiovascular Medicine, Page-149; 8th edition, 2008.

4. Dhingra R, Ho Nam B, Benjamin EJ, Wang TJ, Larson MG \& D' Agostino S 2005, Cross-sectional relations of electrocardiographic QRS duration to left ventricular dimensions: The Framingham Heart study, J Am Coll Cardiol, vol.45, pp. 685-9.

5. Emkanjoo Z, Esmaeilzadeh M, Hadi NM, Alizadeh A, Tayyebi M \& Sadrameli MA 2007, Frequency of inter and intra ventricular dyssynchrony in patient with heart failure according to QRS width, Europace, vol.9, pp.11716.

6. Prinzen FW, Cheriex delhaas T 1995, Asymmetric thickness of the left ventricular wall resulting from asynchronous electric activation: A study in dogs with ventricular pacing and in patients with left bundle branch block, Am Heart J, vol.130, pp.104553.
7. Shenkaman HJ, Pampati V \& Khandelwal AK 2002, Congestive heart failure and QRS duration: establishing prognosis study, Chest, vol.122, pp.528-34.

8. Schneider JF, Thomas HE, Kreger BE, et al. Newly acquired right bundlebranch block: The Framingham Study. Ann Intern Med. 1980; 92:37-44.

9. Schneider JF, Thomas HE Jr, McNamara PM, Kannel WB. Clinicalelectrocardiographic correlates of newly acquired left bundle branch block: The Framingham Study. Am J Cardiol. 1985; 55:1332-1338.

10. Schneider JF, Thomas HE, Sorlie P, et al. Comparative features of newly acquired left and right bundle branch block in the general population: The Framingham study. Am J Cardiol. 1981; 47:931-940.

11. Kreger BE, Anderson KM, Levy D. QRS interval fails to predict coronary disease incidence: The Framingham Study. Arch Intern Med. 1991;151;1365-1368.

12. Dhingra R, Pencina MJ, Wang TJ, Nam BH, Benjamin EJ \& Levy D et al., 2006, Electrocardiographic QRS Duration and the Risk of Congestive Heart Failure, Hypertension, vol.47, pp.861. 